Ethiopian Journal of Environmental Studies \& Management 9 (1): 80 - 96, 2016.

ISSN:1998-0507

doi: http://dx.doi.org/10.4314/ejesm.v9i1.8

Submitted: September 07, 2015

Accepted: January 13, 2016

\title{
A PARTICIPATORY GIS APPROACH TO SPATIAL MODELING FOR SLUM UPGRADING: THE CASE OF EPWORTH WARD 4, ZIMBABWE
}

\author{
*TOGAREPI, S., MASARIRA, T.P. AND PHIRI, L. \\ Department of Geoinformatics and Surveying, University of Zimbabwe, P.O. Box MP167, \\ Mt. Pleasant, Harare, Zimbabwe
}

\begin{abstract}
The most prominent problem of rapid urbanism in Harare is the development of slums and Epworth is a notable example. The quality of planning and decision making in the participatory slum upgrading initiative can be sustainably improved by well managed processes of spatial and socio-economic data collection. More so, existing approaches for slum upgrading are built on the basis of collaborative planning and thus community participation. Geographic Information Systems (GIS) tools and support systems should explicitly consider the needs of professional and non-professional stakeholders in slum upgrading process. This study aimed to develop a customized "GIS based slum upgrading system" that would empower the community to participate in the planning and decision making processes involved in slum upgrading. The study involved developing tools that could be used by lay people, to achieve the same results an expert would. To achieve this, a PostgreSQL/Postgis spatial database integrating the spatial and enumeration data component was developed as the backend with a front end developed using VB.Net. A Map Control tool was imported from Map window 4.7 for displaying and interacting with spatial data. Techniques such as buffering were incorporated in the system to allow users to check for structures within a given distance of a feature. The system also provided a tool that allowed users to select an area and calculate the number of stands that can be obtained after inputting parameters like stand size and type of road. The system provided for tools that calculate statistical values e.g. determining the population as well as the number of households in a selected area. Users could also query for socio-economic data by selecting spatial features. This provided flexibility in terms of the interaction of the users with the data. The system proved that with user oriented GIS system it is possible to develop tools that can be used by lay people especially those in slums to formalize their areas and obtain security of tenure.
\end{abstract}

Key Words: Slum upgrading, Participatory GIS, Security of tenure

\section{Introduction}

Zimbabwean cities are witnessing massive population growth as more people migrate to urban areas in search for better living standards, job opportunities, higher education and other facilities that cities offer. This phenomenon is referred to as urbanism (Patel, 1988). Massive urbanism has posed enormous challenges to governments and to local authorities as

*Corresponding Author: Togarepi, S.

Email: stogarepi@gmail.com 
they lack tools and facilities to deal with this inevitable expansion. More so, the government and the local authorities have failed to incorporate planning models that cater for the urban poor communities. As a result, they have failed to provide the basic amenities that make these communities habitable. Some of these factors can be attributed to the sprouting of informal settlements (slums) across Harare. Epworth is a notable example of such informal settlements. In the year 2001 over 900 million people lived in slums around the world. If nothing is done to prevent the growth of the slums, the estimated number of slum dwellers will increase to about two billion by the year 2030 (UN-Habitat 2003). Governments often contribute to slum growth by failing to provide for the needs of the poor and incorporating them in urban planning. Some governments lack the capacity to react rapidly to urbanization quickly enough or lack the tools to deal with the situation.(UN-Habitat 2014).

Formalizing informal settlements and redeveloping them to become sustainable communities was found to be one of the prominent solutions towards dealing with the sprouting of slums and this process is called slum upgrading. However, experience accumulated over the last few decades suggests that in-situ slum upgrading is more effective than resettlement of slum dwellers and should be the norm in most slum-upgrading projects and programmes (UN-Habitat 2003). 'Slum upgrading' is the practice of alleviating poor living standards of slum households by providing water supplies, sanitation, road access to each homestead, housing upgrades and other basic urban services, as well as securing tenure to the settlers. Informal areas are continuously improved, formalized and incorporated into the cities. The processes include providing slum dwellers with the social, economic, legal, institutional and community services available to other citizens in the cities (Materu and Sietchiping 2001; Rema 2012). This approach is currently being undertaken in Epworth ward 4 in Zimbabwe by the Zimbabwe Homeless People's Federation (HPF) and Dialog on Shelter (DOS). These organizations are involving the community and other stakeholders to plan and upgrade the settlement. Participatory slum upgrading (PSUP) promotes improvement of existing settlements (in-situ upgrading) and upgrading of services should be done by the local government with the involvement of all parties which include residents, national authorities, community groups and businesses (UN-HABITAT 2000).

The upgrading process undergoes several processes such as enumeration, spatial data collection using GIS techniques, analysis of data, layout design, approval, and surveying and finally securing tenure for the residents. The collection of this data through the use of GIS techniques is not enough if it cannot be used for analysis and if the community does not have a feel of ownership, due to marginalization in the process of upgrading the slums. Abbot (2003) notes that "GIS should not be used only as a technical tool to underpin physical development; it should be viewed as a tool that liberates local authorities, communities and professionals, and allowing interaction between the spatial, physical elements on one hand, and the social and economic opportunities on the other, in a three-dimensional virtual environment". (Abbott, 2003) mentioned that "Upgrading large-scale informal settlements is most efficient through applying spatial information technologies. 
Slum upgrading has to mainly focus on the social and economic development of the community and GIS must support this process. The ability to represent informal settlements spatially, through the medium of a GIS, is an important component of the upgrading process. Furthermore, the visual representation of spatial and attribute data delivers the framework for the application of geospatial information management systems in the slum upgrading process. Therefore, the use of GIS in informal settlements development is now greater than before all over the world (Zeilhofera et al., 2008).

Implementing a GIS approach in management and analysis of spatial and enumeration data is the key towards sustainable slum upgrading process. The use of GIS provide the platform to integrate spatial and socio-economic data, visual representation of data, efficient management of geospatial information, tools to analyze and aid in decision making (Saleh and Sadoun 2006). The local government with the participation of all parties which include the residents, community groups, businesses, planners and local authorities should have an understanding of spatial information and impacts posed by each decision made in the procedure in order to have sustainable management and planning. In harmony with the Mapping for Change International Conference held in Nairobi, Kenya September 2005, Participatory GIS (PGIS) was mentioned to be a practice of developing another possibility to urban planning, geospatial information management and communication of such information to the community.

In South Africa, development partners, local authorities in partnership with the communities developed a GIS based approach to informal settlement upgrading which aimed at empowering the community, both through the provision of detailed information on the community and then by the use of that information to support their negotiations with the local authority (Abbott, 2003). Furthermore, PGIS has the ability to empower communities in relation to developing solutions to spatial planning problems, provided it is used adequately (McCall, 2003). Of late there has been a growing call for the use of information collected from the actual residents of the settlements for analysis prior to the upgrading of the settlements (Lefulebe et al., 2012). Its effectiveness however depends on acceptability. The implementation of GIS in slum upgrading can be complex and one of the barriers for this process to take place can be the acceptance of this tool, not only by the government but also by the community (Carazzai 2002).

Consequently, the need for a custommade GIS based application which manages, communicates geospatial information and allows the community, planners and other decision makers to view and analyze both spatial and socioeconomic data interactively before designing the final plan becomes eminent. The GIS custom made system should therefore strive to be as user friendly as possible and abstract the users from the intricacies behind the technology. This research therefore, seeks to develop a GIS system that will provide the GIS functionalities required to cater for all stakeholders in the slum upgrading process using a participatory approach.

\section{Description of the study area}

Epworth is situated about $15 \mathrm{~km}$ from Harare CBD on the south east part. Figure 1 shows the study area map. Epworth is found on Latitude $17^{\circ} 53^{\prime} 22.04^{\prime \prime S}$ and Longitude $31^{\circ} 9^{\prime} 41.01 " \mathrm{E}$. In terms of 
population it is the largest informal settlement in Zimbabwe, comprising of seven wards and a population of more than 130000 people. In the late nineteenth century, The Methodist Church established Epworth as a mission station on land where the community was already resident. By 2010 , more than 6,500 families had settled in this one area of Epworth alone (Chitekwe-Biti, et al., 2012) The choice of the study area was influenced by the availability of data complimented by the fact that Dialogue on Shelter and its partners were also in the process of implementing a similar project.

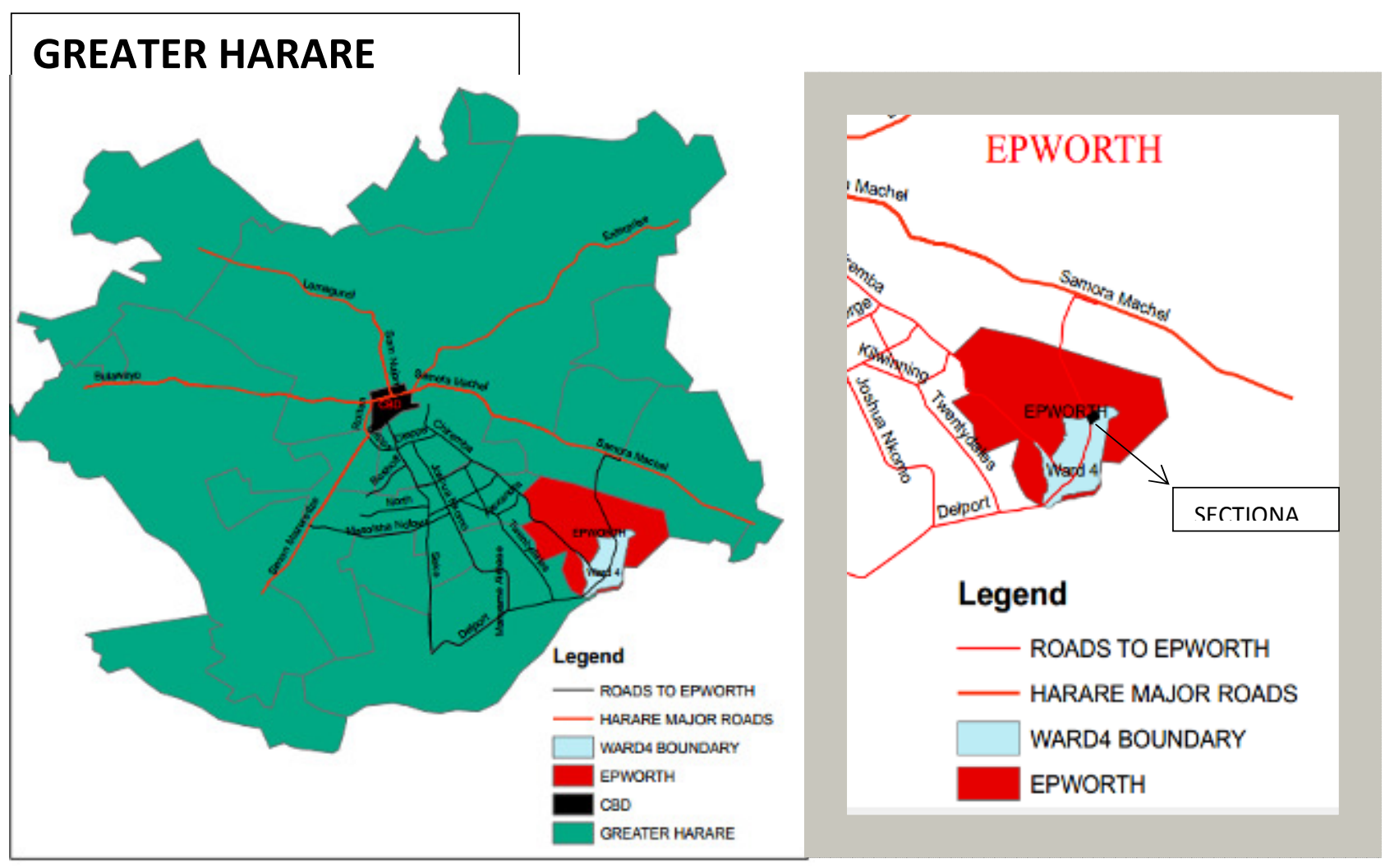

Figure 1 .Epworth ward 4 study area map

\section{Methodology \\ Data availability}

The datasets for this project were availed by HPF and DOS since they were already undertaking slum upgrading projects in Epworth. The data included datasets for the stands, the enumeration data components and the Quick bird image covering the study area. Other datasets like roads, building structures, schools and water points were extracted from the Quick bird image with a spatial resolution of $0.61 \mathrm{~m}$. The digitizing process was done using ArcGIS. The stand boundaries were identified by means of an adjudication process and each structure on a stand was numbered after the stand number. This was necessary for linking the two datasets in the database. It is important to note that some of the data was captured by the lay community in Epworth hence had a lot of anomalies. The enumeration data was 
collected by the community with the help of DOS via questionnaires. For this project data from 213 homesteads which constituted 423 households with a population of 926 was used. The total area for the area understudy was 12.1234 hectares and comprised of 199 stands. It captured the socio-economic data of all the residents in ward 4 . The enumeration data also required cleaning to eliminate duplicate entities. These errors were corrected so that the structure numbers were uniquely identified. This identifier was used to link the spatial data to the corresponding enumeration data as well as the stand data in the database. Table 1 shows the available datasets and their description

\section{Data processing}

The spatial data that was obtained from HPF was further processed with regard to topology checking, data validation, extraction of missing roads, reformatting and cleaning of road data, adding missing stand numbers as well as verifying and making unique all the stand numbers by removing duplicate information. The land use type i.e. residential, commercial and schools was added to the stand attribute table so as to facilitate the rendering of the stands on the map as well as to allow analysis on stand usage.

Table 1: Description of data made available by HPF and DOS

\begin{tabular}{lll}
\hline Available data & Data type & Data description \\
\hline Stand boundaries & Polygon & Location of stands \\
Enumeration /demographic data & Attribute data & Demographic and socio-economic data \\
Quick bird image & Raster & Spatial resolution of $0.61 \mathrm{~m}$. \\
Schools & Point & Schools location \\
Water points & Point & Location of water points \\
Building structures & Polygon & Location of building structures \\
Roads & Polyline & Location of roads \\
\hline
\end{tabular}

\section{Requirements Analysis}

Discussions and presentations were used as requirements gathering techniques. The stakeholders involved were the Homeless People's Federation and Dialog on Shelter, the Epworth ward 4 community, planners, surveyors, GIS practitioners, academics from the University of Zimbabwe and local board representative. In total there were 34 people representing these organizations. From these discussions and presentations, user requirements were drawn that guided the development of the application.

\section{Database and application development}

A Spatial Database Management System (SDBMS) is optimized for the storage and querying of related objects in space and through the structured query language (SQL) it can handle spatial queries. The Postgresq1/Postgis database was chosen for this project. Microsoft.Net was used for the development environment, while Map window was chosen for its capability to add GIS capabilities to the user's existing software product through its ActiveX component. Further, geo-processing components are available for .NET-compatible environments and other languages (Marchionni 2008). Map window was developed to address the requirements for GIS programming tools thus eliminating the need to purchase GIS systems while empowering programmers to develop GIS applications customized for their research needs (Sadoun et al., 2015). The other components of Map window which were 
employed in this research were MapWin that interfaces a Dynamic Link Library (DLL) with a "Plug-in Interface". It allows the developer to write plug-ins to the main application. This may be done from any programming language, which supports the creation and use of Microsoft .NET 2.0 Dynamic Link Libraries (DLL). MapWinGeoProc a .NET library of geoprocessing functions, including tools for managing projections, clipping and buffering (Sadoun et al., 2015).

NPGSQL is another component that was used. It is a .Net Data Provider for the PostgreSQL Database Server. It allows a .Net client application (Console, Windows Forms, ASP.NET, WebServices) to send and receive data with a PostgreSQL server. It is actively developed based on the guidelines specified in the .Net documentation. In other words it works as a connector string that allows connection between the application and the database
(Cooley 2008). Athree tier architecture was used for creating the application. The Database tier contains all relations and constraints along with its query processing languages assemblies. The Application tier consists of the application server and programs, which enables access to the database and executes commands. To the system user this application tier is an abstracted outlook of the database. The user tier is unaware of the existence of the database beyond the application, while the database tier is not aware of any other user beyond the application tier hence the application tier works as a mediator between the two. The User Tier is defined as the graphical user interface (GUI) where the user can query the database without the knowledge of the existence of the database or the application designs beyond this layer. At this layer, multiple views of the database can be provided by the application.

\section{Results and Discussion}

The spatial database and application development

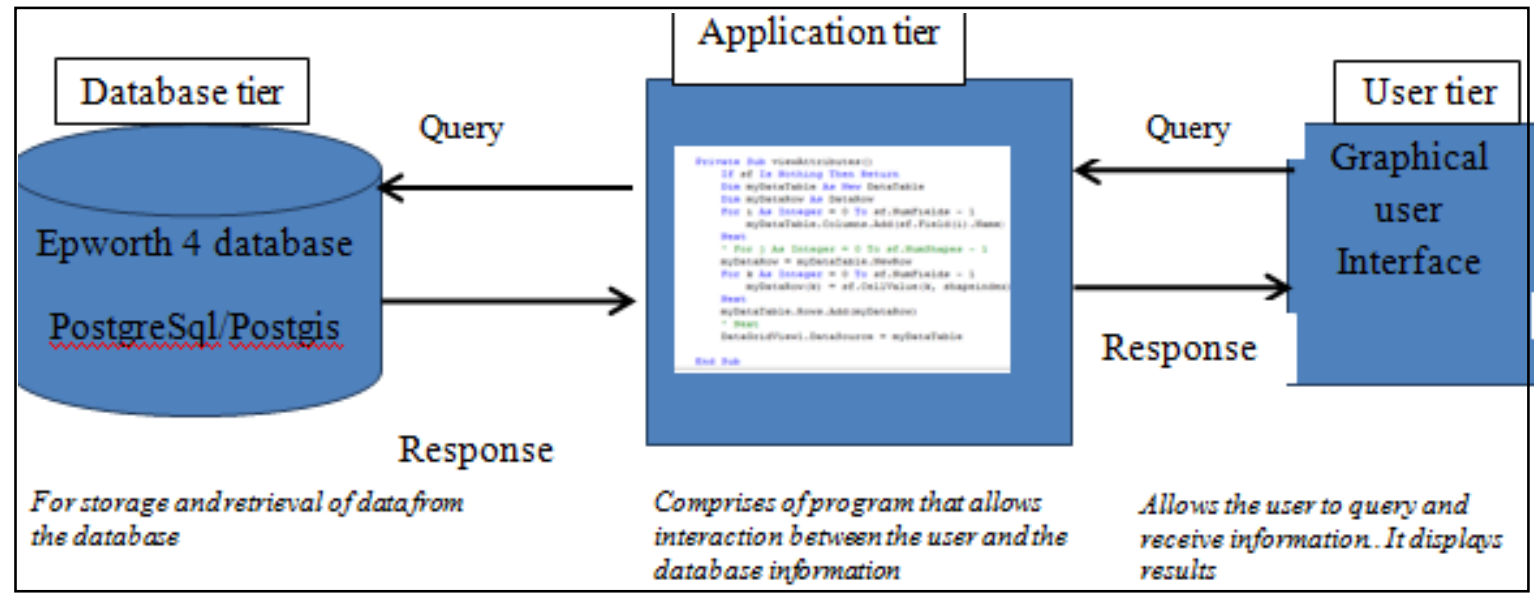

Figure 2: Three tier architecture

This research revealed that it was possible to integrate the spatial and enumeration data allowing concurrent querying of the two datasets. The Spatial database was populated with tables containing the roads, structures, stands and water points. The stand and structure data was linked with enumeration data to allow 
for the analysis of both datasets at the same time. The linking of the stand, structure and enumeration tables was done through code. In this case if one selects a stand on map window the system will pick the structure number of the feature and then use it to relate with the structure number in the enumeration table making it possible to display enumeration data for a structure on the selected stand.

\section{User Requirements}

The results of the user requirements analysis gathered from the stakeholders indicated that the system should be able:

i. to store both spatial and enumeration data,

ii. to centrally store data and enable users access for updating both the socioeconomic and spatial data respectively,

iii. to link and interactively query the spatial data with the corresponding enumeration data,

iv. to allow spatial and enumeration data to be retrieved and analyzed simultaneously,

v. to consist of GIS functions which allow analysis of data e.g. buffer function and distance measurement,

vi. to enable map visualization of spatial and enumeration data,

vii. to calculate statistical values e.g. determining the population, number of households, area of a selected region,

viii. to consist of a friendly Graphical User Interface (GUI) which can be easily used by the lay community in planning and decision making.

The above requirements show that the stakeholders required an application that has got GIS functionality that commercial GIS software offer. However, the difference being that the users require an application which abstracts them from the intricacies of a myriad of GIS tools that are offered by the commercial software. Existing approaches for informal settlements upgrading are built on the basis of collaborative planning exercise and demanding community participation. Consequently, tools and support systems should explicitly consider the needs of professional and non-professional actors of slum upgrading (Sliuzas and Kuffer, 2004). To a greater extend the system managed to achieve the user needs as set out in the user requirements. The discussion of the results below will be centered on the user requirements stated above.

\section{The GIS functions supported by the system}

The system comprises of GIS tools which are simplified and specific for slum upgrading. These include display and classify, buffer, calculations, attribute and spatial query. These functions enable flexibility in data selection and display, to allow physical planners and decisionmakers to view and analyze the planning scenarios before drawing the final plan. This compares well to the flexible relational model made possible through the use of a GIS-based spatial data management system (Abbott, 2003).

\section{Display and classify tools}

The display tool uses the Map control tool on the GUI to display spatial data contained in the Epworth4a database. Through the map window map control, the spatial data is displayed on the map control automatically as the application loads. The features of each layer are classified according to a chosen attribute. The structures layer and the stands layer are classified by structure and stand number respectively. The two layers are rendered differently on the map for easy of identification and analysis of features. 


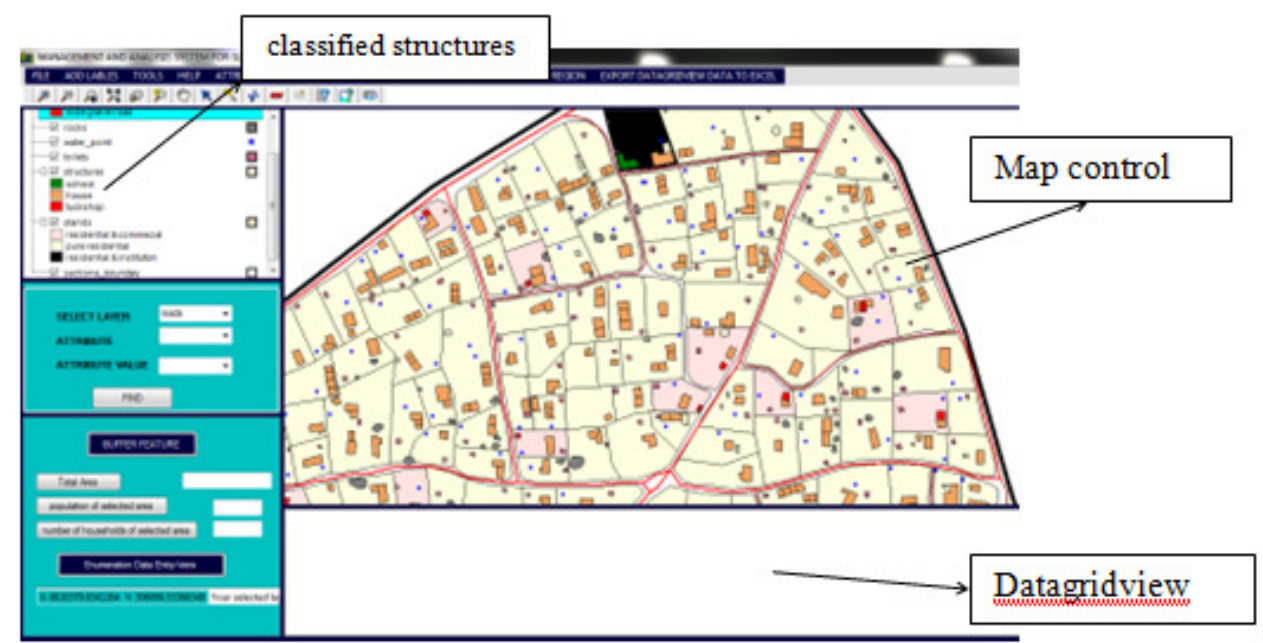

Figure 3: Display and classifying data

The classification of the structures was based on structure use i.e. whether it is a tuck shop, house or school. The classify tool will help the community and stakeholders to visualize the spatial arrangement of the different features and identify suitability of location. Displaying data in this manner will help users to access individual map components to extract information, and functions to process, manipulate, or summarise that information. The spatial data visualisation may also be used to explore the data for more insight. Displaying information helps planners communicate geospatial information to residents (Rosario Giusti, 2009). 'Using GIS simplifies the performance of spatial analysis and the preparation of excellent graphics which lend an aura persuasiveness to policy reports that public and private institutions prepare' (Obermeyer, 1998).

\section{Attribute Query}

One of the user requirements was to provide tools that allow users to query data from the database. The application managed to provide for this requirement through the "attribute query" function which is found on the toolbar. This tool allows users to query the database using any named attribute in the database. The example in figure 4 show an attribute query were a user attribute r_name was used to select a registered owner Samuel Sithole from the database and display all the properties he owns in Epworth Ward4 in a datagrid view. In this example the query returned one record for this stand owner. This query is handy for the lay person as it displays all the attribute values for the selected named attribute. The advantage of listing the attribute values is that users will not misspell the values that they are searching from the database. All the stands that are owned by Samuel Sithole are also highlighted on the Map Control window. Figure 4 shows the results of a query relating to Samuel Sithole. When the users click on the find button information relating to Samuel Sithole is displayed on the datagrid view. 


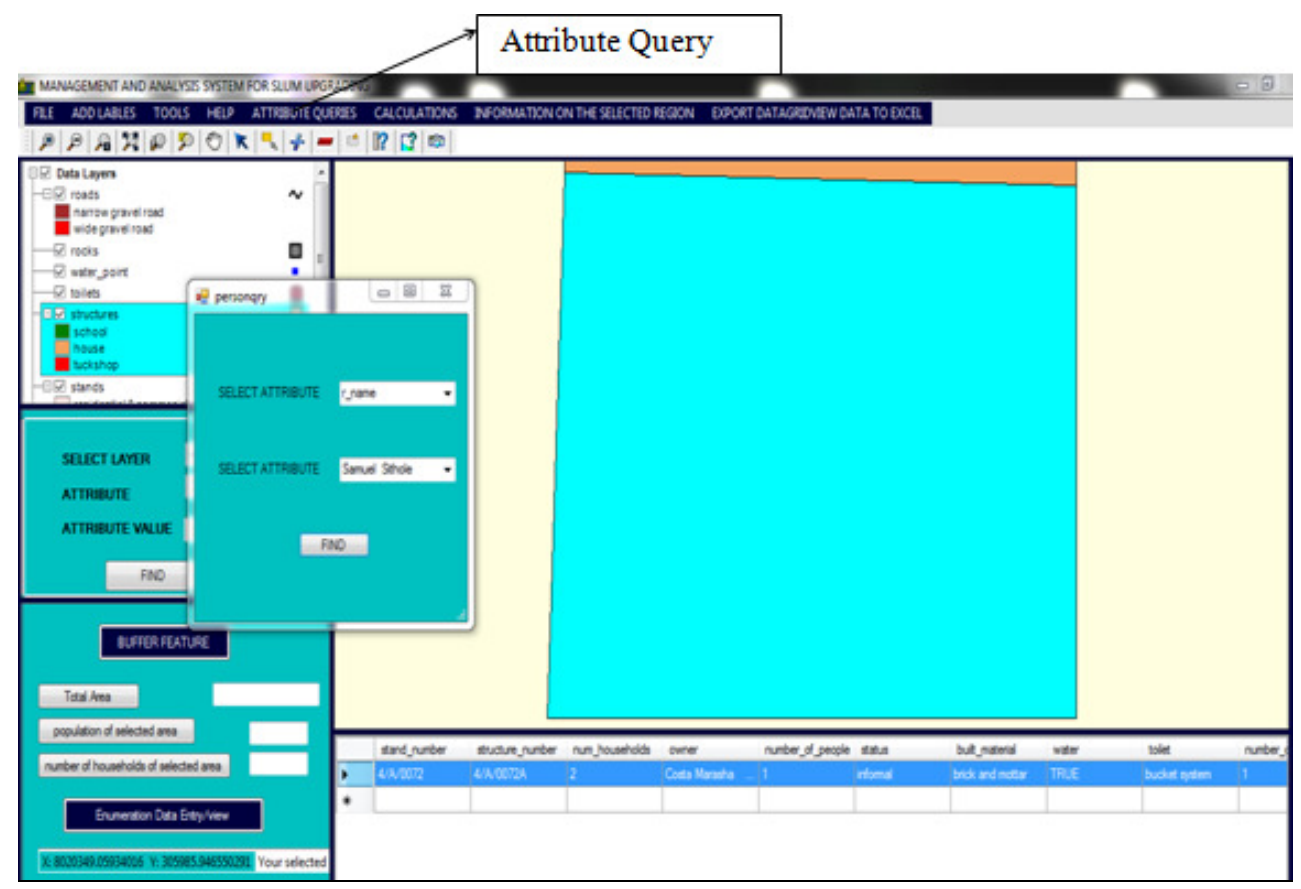

Figure 4: Attribute query using owner name

\section{Select and View Attribute Data}

The select function allows the user to select features in a region to be planned. The attribute information relating to the selected features is displayed on the data grid view. More information of the selected structures or stands is accessed by clicking "information on selected region".
The information retrieved from this includes total population, number of households, and number of people for each age group. Such information aids in decision making for example deciding appropriate location for a scratch. The aqua color shows all the selected features of interest

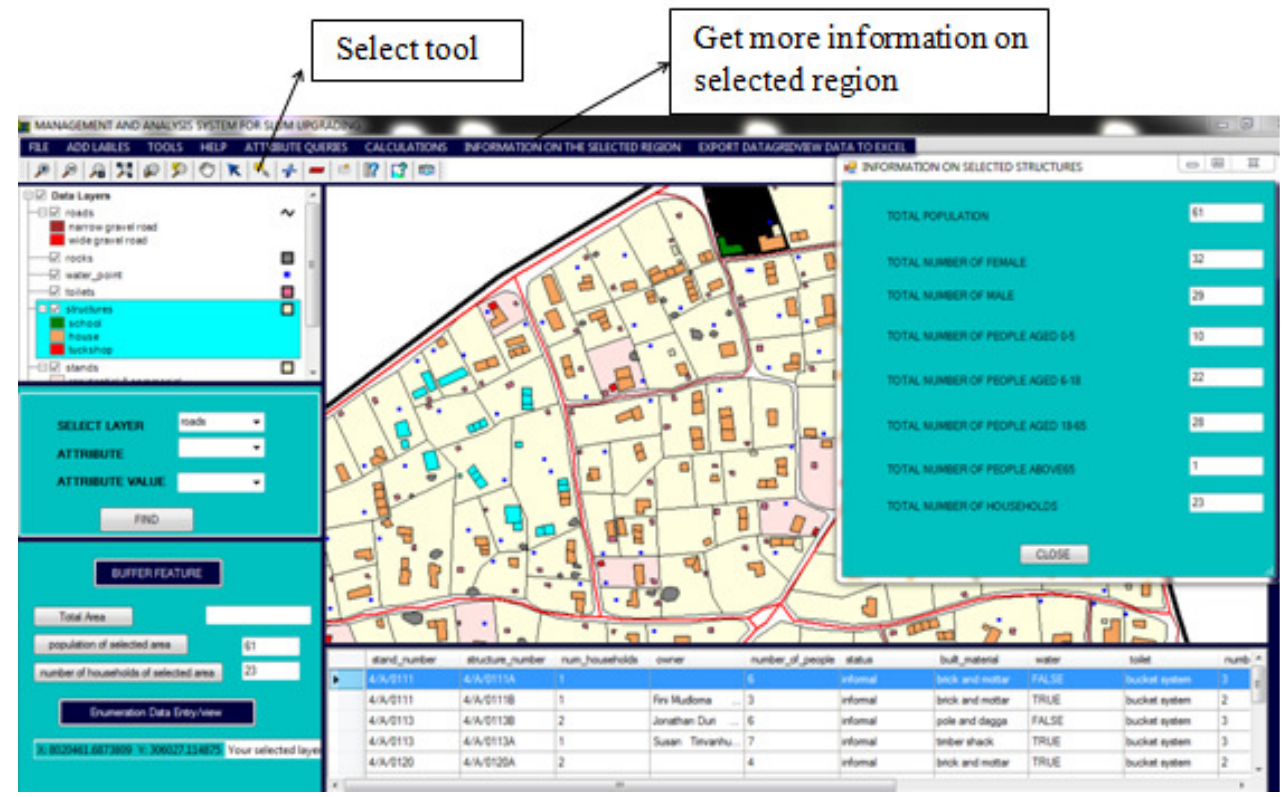

Figure 5: Selected structures and information relating to the structures 


\section{Buffer Tool}

The buffer tool allows the user to specify the buffer type and enter the buffer distance. Upon execution of the tool, selected structures that are within the specified buffer distance are drawn in aqua color. The buffer tool offers three options from which the buffers can be created, namely the:
1. Select structures by distance from all existing roads,

2. Select structures by distance from a particular road,

3. Select structures by distance from a specified structure with a special use i.e. schools, tuck-shop etc.

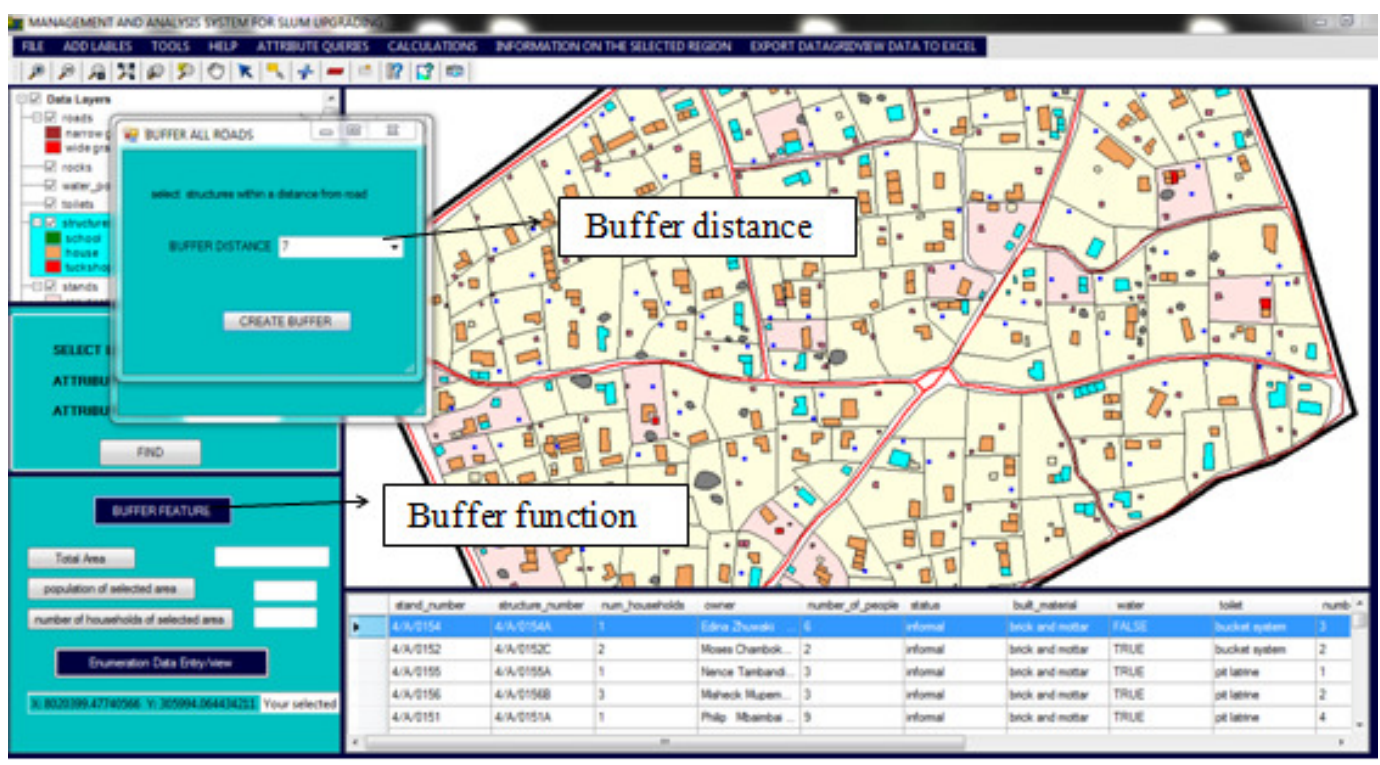

Figure 6: Shows selected structures which are $7 \mathrm{~m}$ from each road

Figure 6 is an example of a buffer showing all structures that are within $7 \mathrm{~m}$ of any road in the study area. While the user can select features that are within a certain distance from all roads. The tool also offers an option to select features that are within a given distance from any road. The features that fall within the selected buffer distance are displayed in a datagrid view and also highlighted on the Map control window. The results can be used as a point of discussion by the community in their planning process and changes made in line with planning regulations if they do not fall within the stipulate distance from the selected road. 


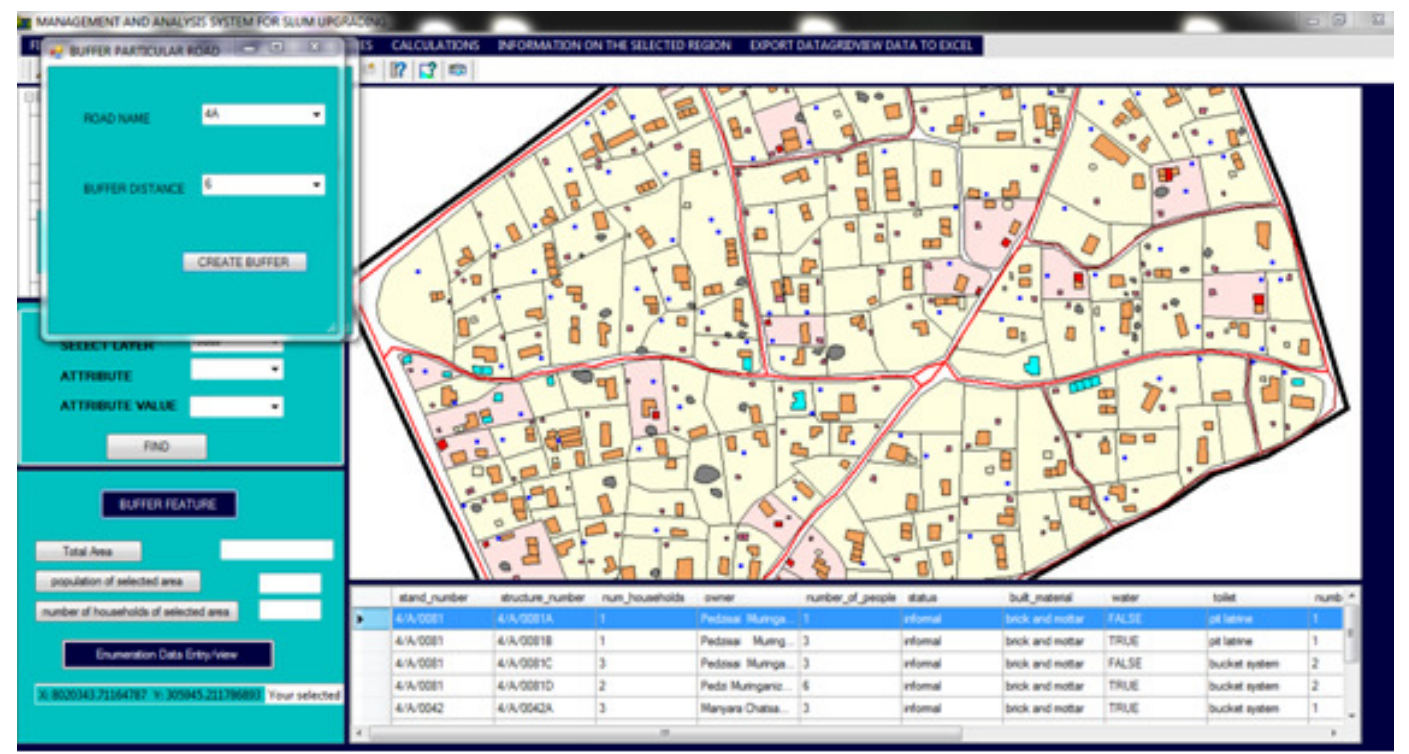

Figure 7: Shows selected structures that are within $6 \mathrm{~m}$ from road 4A

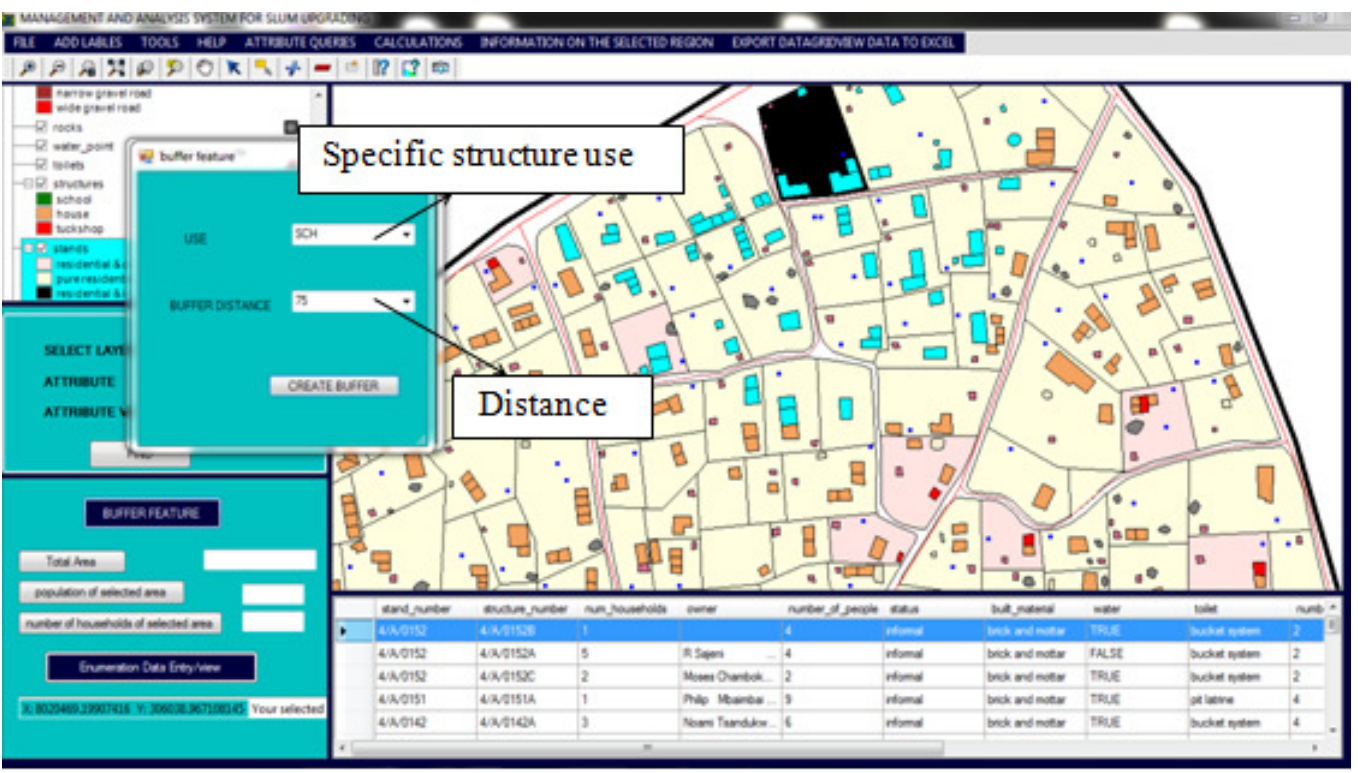

Figure 8: Selected structures within $75 \mathrm{~m}$ from a school

The study area has one stand reserved for a school and one of the requirements was to offer functionality that allows users to be able to find the service area of special areas like schools. The buffer tool as shown in Figure 8 allows users to select all structures that with a given distance of the selected school. This feature will make planning very easy as the population of the selected features will also be displayed by age group. The buffer tool in this regard makes analysis of the different layers possible. "In order for a buffer analysis to be effective, the created buffer zone map has to be intersected with other layers to extract information on the buffered zone" (Lefulebe et al., 2012).Comparing to this, the system buffer function is developed in such a way that the buffer results will give required information on the buffer zone 
through selecting structures intersecting the buffer zone.

\section{Calculation Tool}

The slum upgrading process will result in the formalization of the area in question. As such new stands will be created. Hence a tool that calculates the possible number of stands from a selected region was also a requirement for this application. This tool allows the user to determine the number of possible stands on the selected region to be planned. Several scenarios can be simulated by varying the resultant stand sizes and road types. Different types of roads require different percentages of the planning area as follows: i. Wide roads ( $8-10 \mathrm{~m}$ width roads): takes $20 \%$ of the total area,

ii. Narrow roads (6-8m width roads): takes $15 \%$ of total area,

iii. Foot path (less than $6 \mathrm{~m}$ width roads): takes $10 \%$ of total area.

Lefulebe et al. (2012), stated that Multicriteria Evaluation Analysis employs an organized approach to examine a set of alternatives and this is achieved by ranking options that are more appropriate to the least desirable intentions. The calculation function in the system gives a set of alternatives in determining a number of possible stands in a selected region.

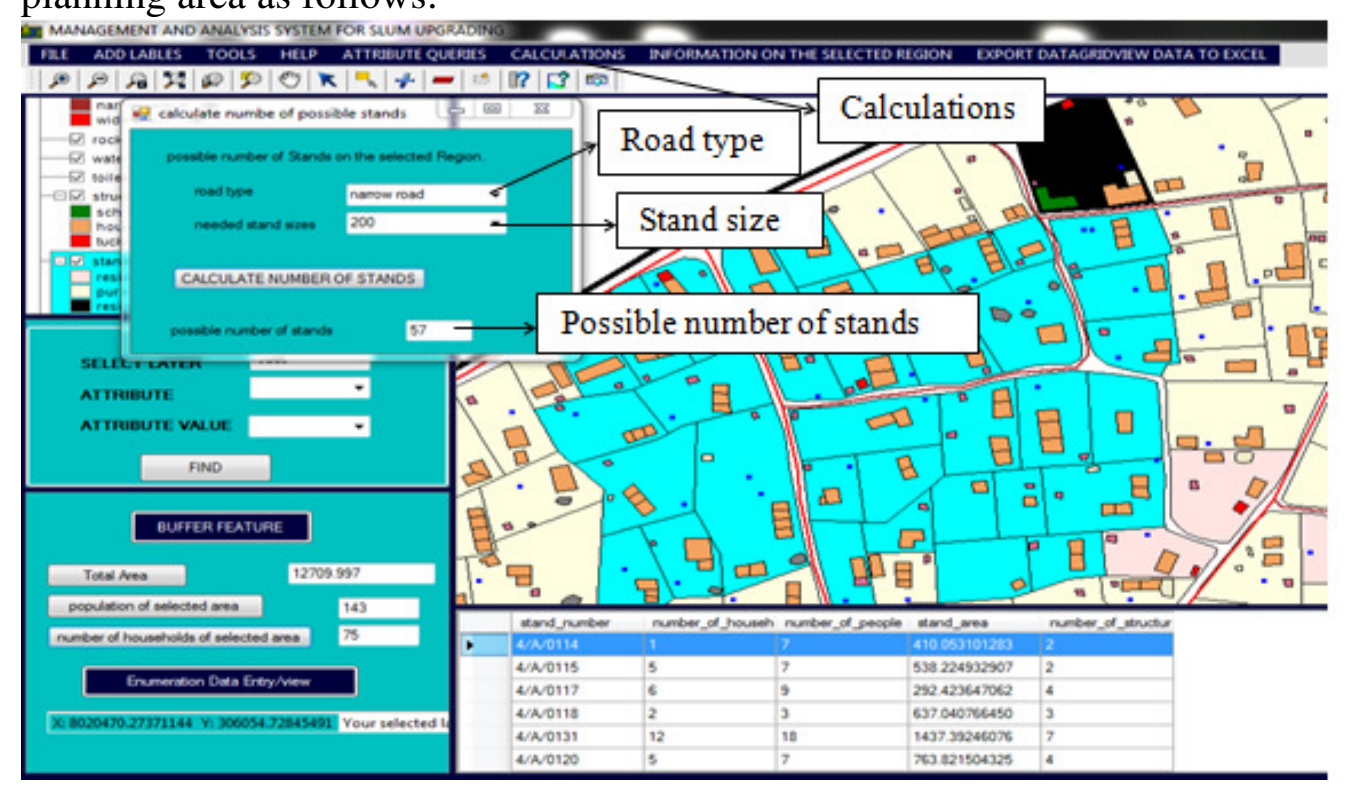

Figure 9 show results for possible stands on the selected region

\section{Demographic information}

The total Area, total population and the number of households within the selected region can be calculated by click of buttons "Total Area" "Population of selected area" "number of households on the selected area " respectively. More information on the selected region that is relevant for planning such as income information can also be viewed. This is illustrated on Figure 10. The function aids the community and the local authorities to negotiate individual stand sizes, amount of money to be contributed towards the settlement upgrading. Negotiations of stand sizes and amount of contributions can be based on the focused number of households, average income per household, available area, type of road that need to be developed, and total population in a region. 


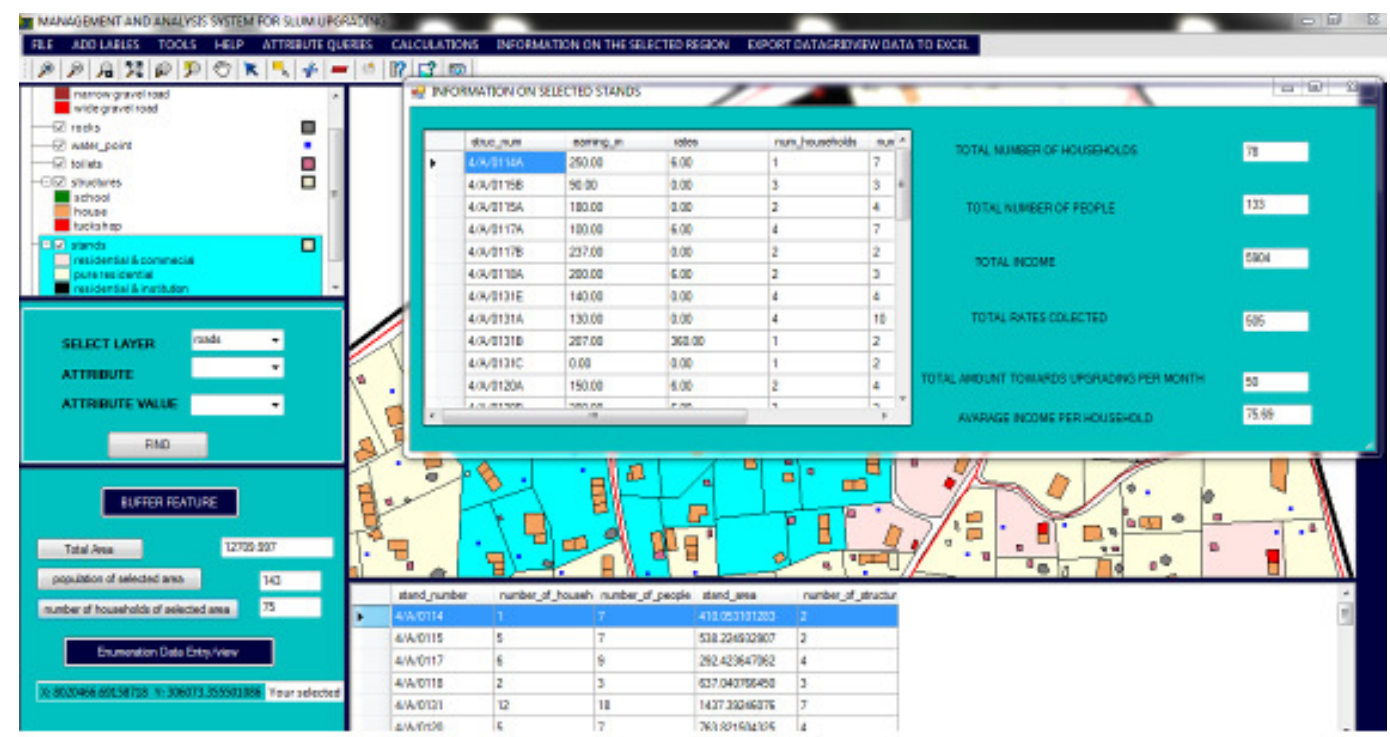

Figure 10: Information on the selected region

\section{Enumeration Data Entry and View}

The function enables the user to create a record of an existing structure or stand. This record comprises of enumeration data. The enumeration data is categorized to form 7 tables which include plot, persondetail, socio-economic, plot-detail, structure, population, utility, upgrading.
This function allows the user to insert or update enumeration data to the already existing tables in the spatial database. This function adds detail to the already existing spatial data i.e. structures, stands. This data is linked by a unique identifier which is the structure number and the plot number.

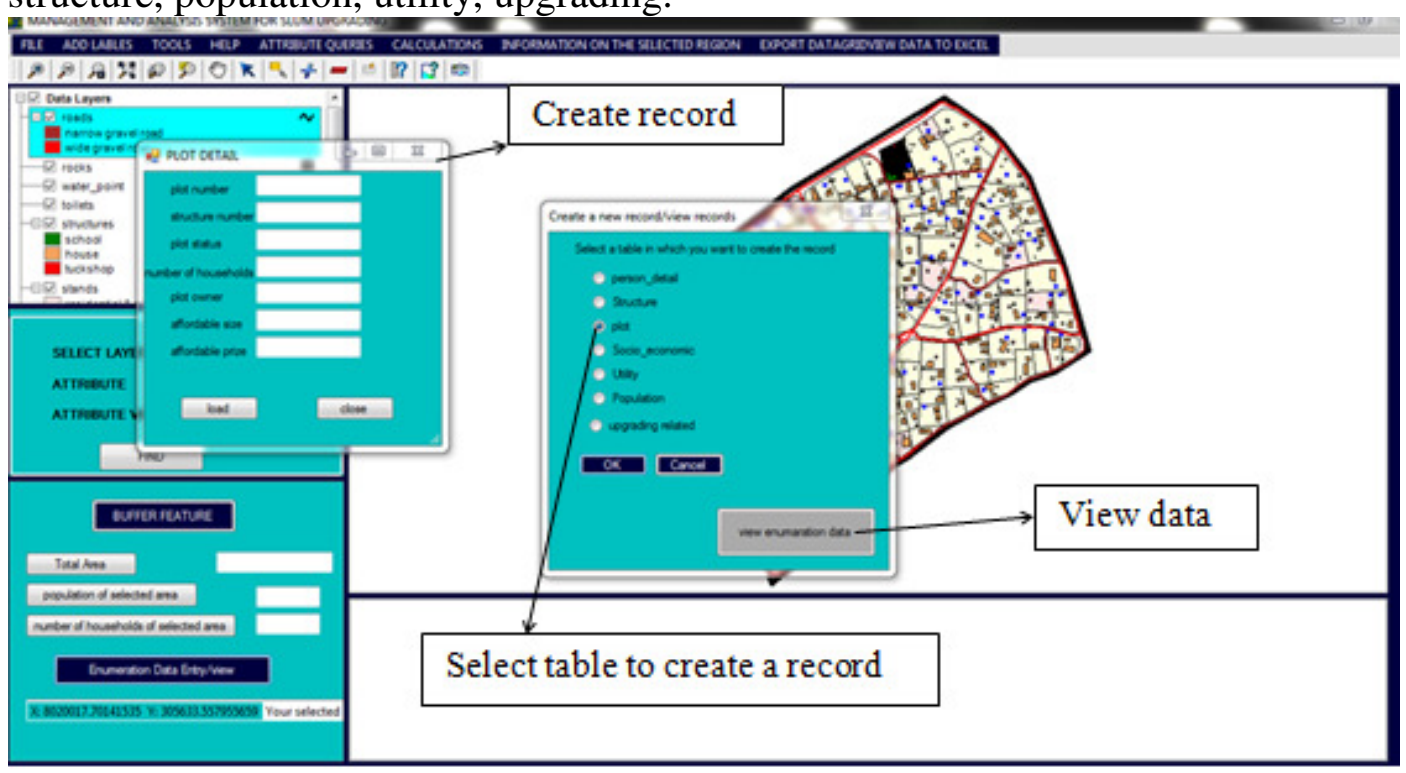

Figure 11: Record creation 


\section{Spatial Query}

In every information management system the user requires to search and retrieve information for example in this application one might ask the system to find a stand where the use is residential and institutional. The result of the query is as shown in Figure 11.

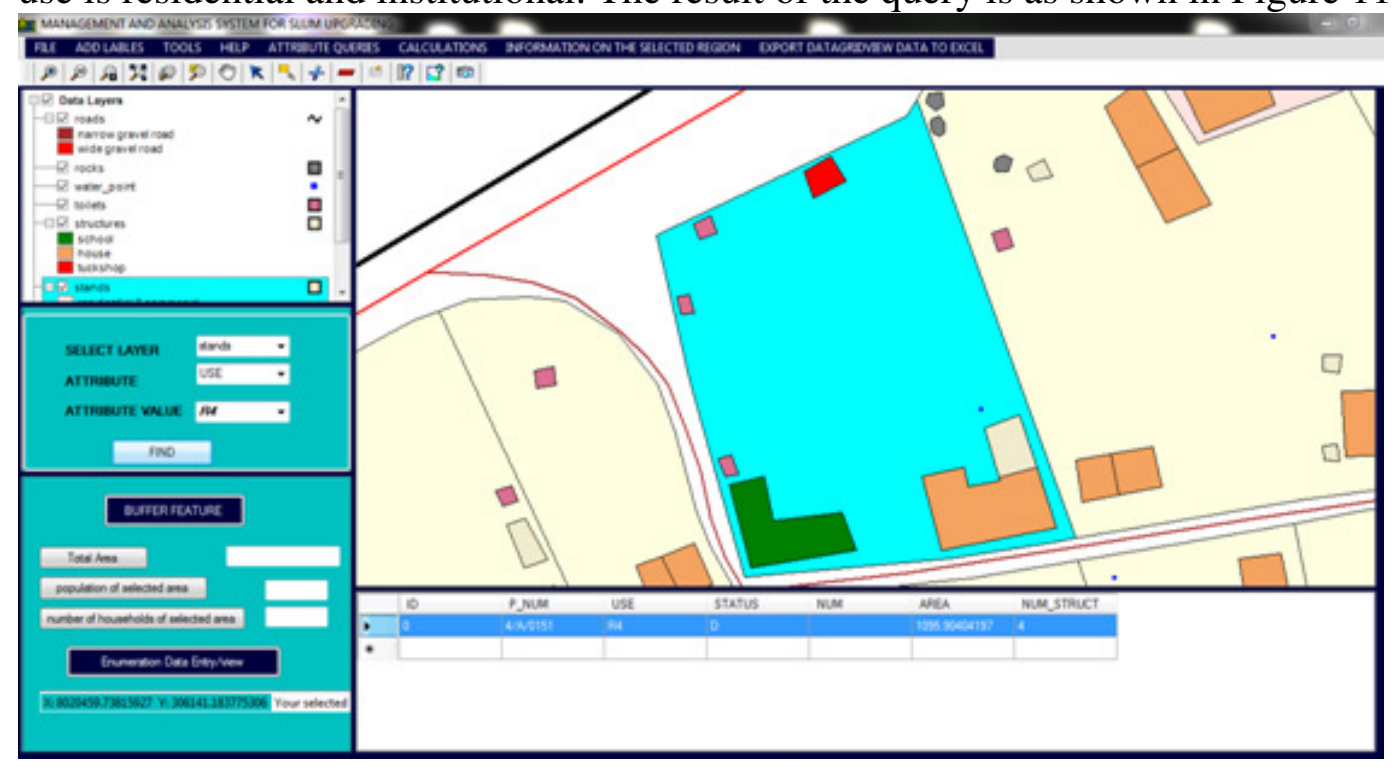

Figure 11 showing result of query by stand use

Decision-makers can make use of the spatial query function to extract meaningful information from stored data. The ability of this system to respond to questions of spatial patterns e.g. orientation of structure, use and location is dependent on spatial query functions (Toosi et al, 2005).

\section{Other Functions}

1. Export data to excel

This function allows user to export data displayed on datagrid view to excel for further analysis.

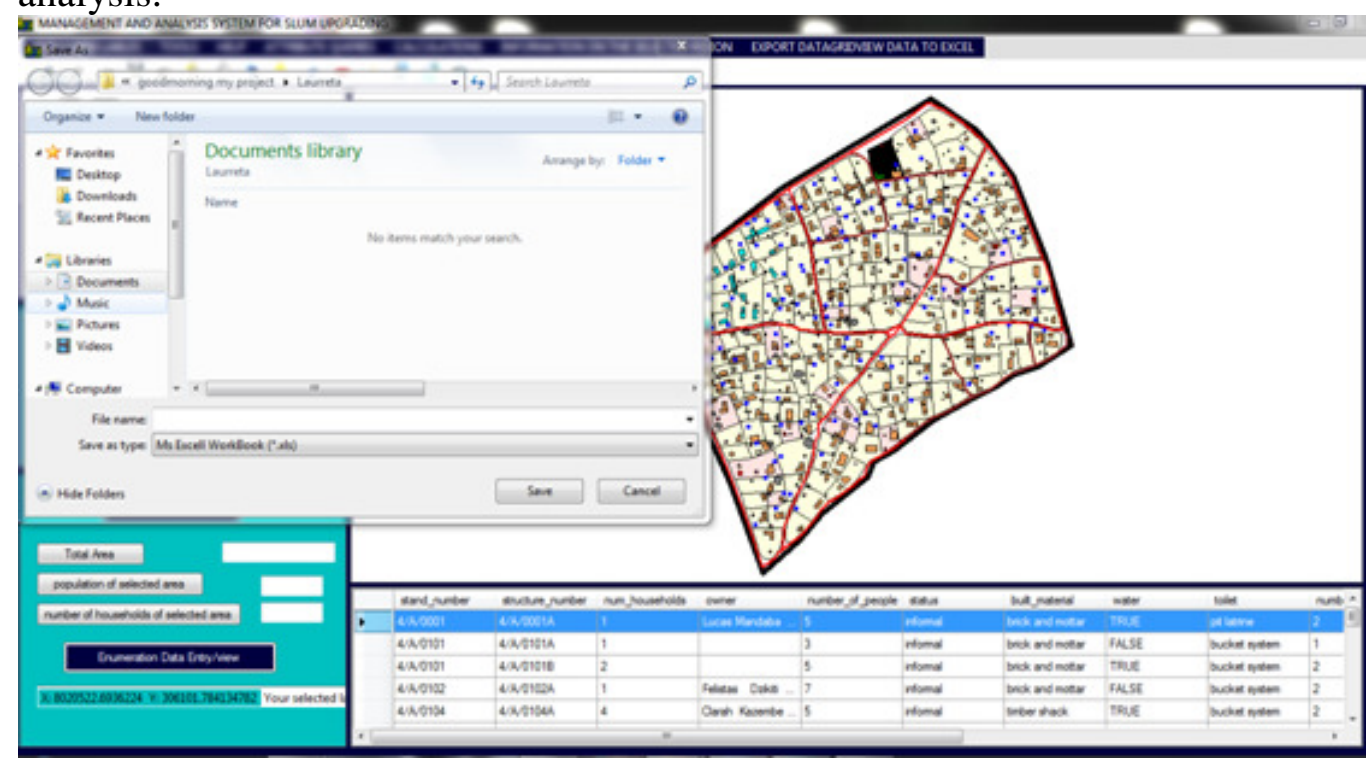

Figure 12 export data to excel 
2. Print Map view: This function allows a user to print or save a map for planning purposes. This will also enable the community and stakeholders to plan the whole region in sections. As a result of that, there will be community participation and harmony between residents as the working groups would be small(Rosario Giusti 2009).

The system has a standard tool bar where users can access additional functionality such as measure, adding layers and printing

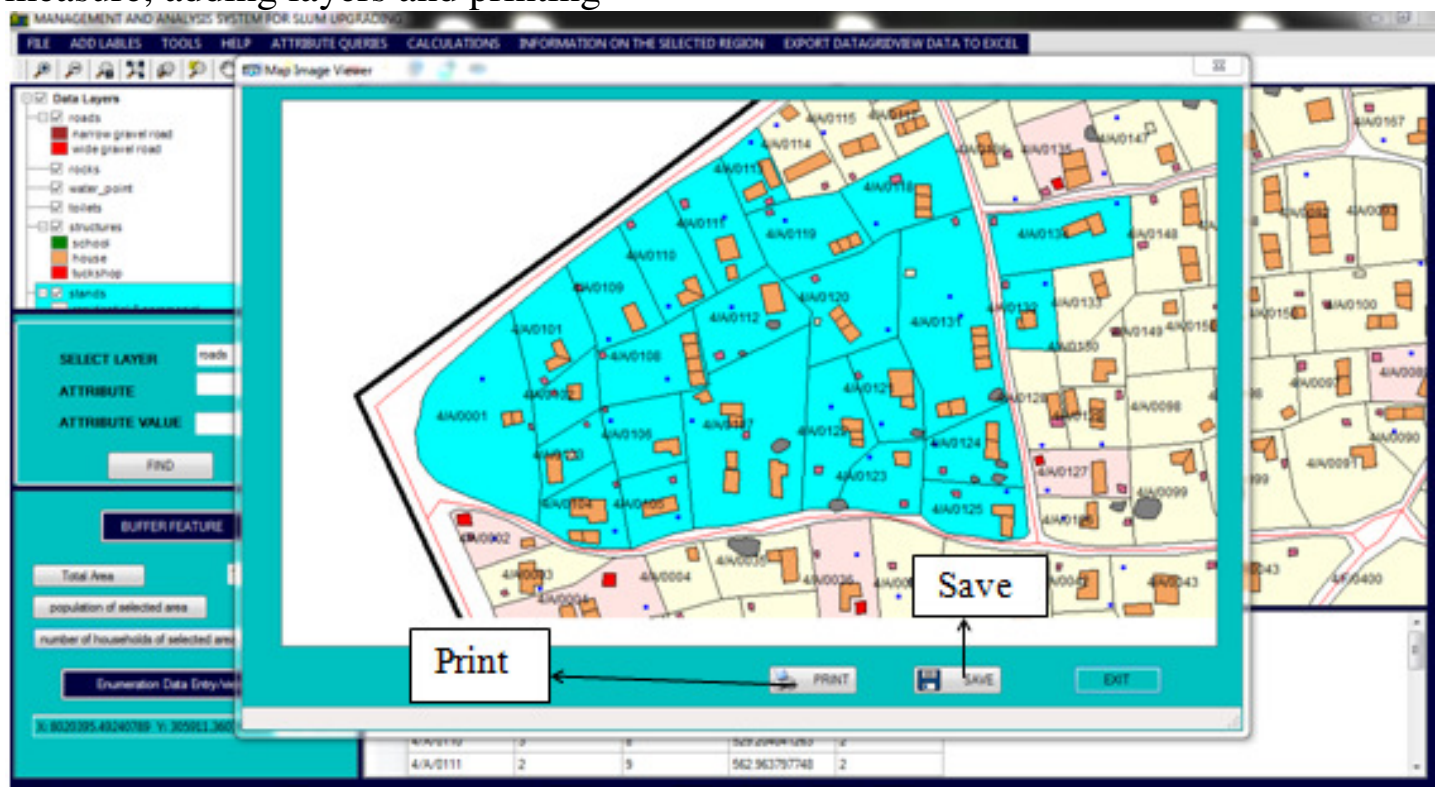

Figure 13: Print map view of the region to be analyzed

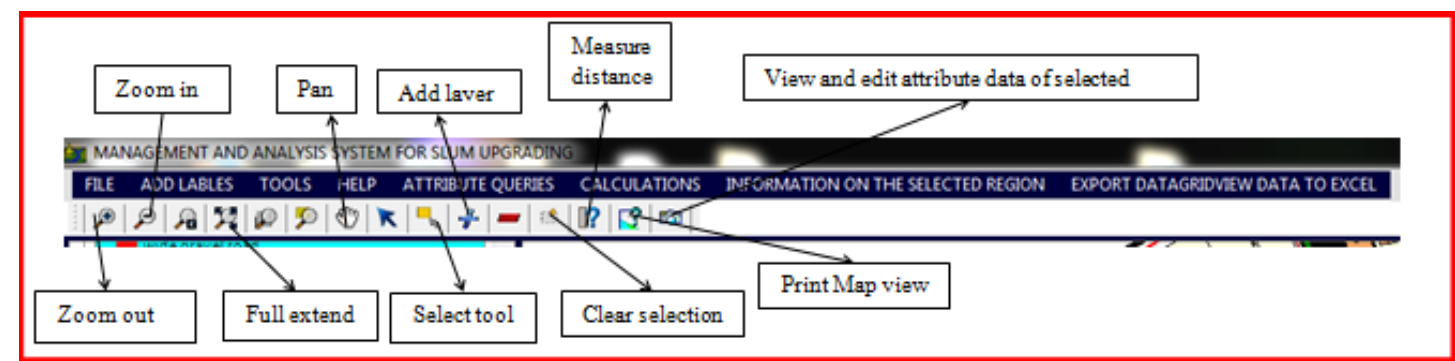

Figure 14: System standard tool bar

1. Add label: This function allows a user to add labels on the selected legend layer

2. Add shapefile: Allows the user to add shapefiles to the Map control

\section{Analysis of system results}

Existing approaches for informal settlements upgrading are built on the basis of collaborative planning exercise and demanding community participation. Consequently tools and support systems should explicitly consider the needs of professional and non-professional actors of slum upgrading (Sliuzas and Kuffer 2004).
To a greater extend the system managed to achieve the project objective as well as the user requirements.

Šliužas 2004 mentioned that "Dealing with slums requires an assimilated planning approach which incorporate strategic planning and decision making with effective and efficient management practices. Given resource limitations 
antagonizing actors in developing countries, it is preferable to develop systems that are inexpensive to construct, stress-free to use and flexible in their application. This infers a partiality for well tested tools and methods that can be combined as required". True to that assertion the system developed for this research managed to keep costs as low as possible as it used mainly open source software for its development. The collection of data was also done by the community. The tools developed are easy to use, facilitates concurrent visualisation of the spatial and socio-economic components answering the user requirements. Furthermore, the system is easy to use as every tool was simplified to enable the community and none GIS experts to use it. This is important as the users will have a sense of ownership of the system since they defined their requirements, were consulted and also participated in the system testing.

\section{Conclusion}

The GIS based information management system for slum upgrading has accomplished the design requirements and hence enable the slum upgrading process using GIS tools. The system functions from the perspective of a peoplecentered approach. It uses GIS to provide the integration of spatial and socioeconomic data, i.e. the linking of spatial data relating to the settlement to enumeration data relating to the people who live in Epworth Ward 4. More so, it provided tools to analyze this data so as to make informed decisions. Ultimately, the system delivered flexibility in data selection, spatial and attribute querying and visualisation of the spatial component, to allow physical planners and decision- makers to view and analyze the planning scenarios.

Furthermore, the system database is centralized thereby accessible to different users at the same time via a computer network. This functionality saves time in the entry of the socio-economic data and it also empowers the physical planning department with information relevant for the layout approval. The system managed to address the need for GIS in planning and decision making in the upgrading process as it does not require users to become a GIS experts to fully utilize it. The involvement of the users in the formulation of the system requirements made its acceptance by the users easy.

\section{References}

Abbott, J. (2003). The use of GIS in informal settlement upgrading: its role and impact on the community and on local government. 27, pp.575-593.

Carazzai, V. (2002). Community Participation and the use of Geo Information in Informal Settlement Upgrading Programs A Case study of Recife. Earth, (February).

Chitekwe-Biti, B, Mudimu, P., Nyama, G, M. and Jera, T. (2012). Developing an informal settlement upgrading protocol in Zimbabwe - the Epworth story. Environment and Urbanization, 24(1): 131-148. Available at: <Go to ISI >://WOS:000303324800011 \nhttp ://eau.sagepub.com/content/24/1/131. full.pdf.

Cooley, J. (2008). Topics History Internals About Npgsql in Japan Deployment of Npgsql Gnu / Linux $<->$ Windows.

Lefulebe, B., Motala, S. and Musungu, K. (2012). GIS mapping and Analysis 
for informal settlement upgrading in Cape Town - A case study of Monwabisi Park. , pp.1-13.

Marchionni, B. (2008). Introduction to Custom GIS Application Development for Windows.

Materu, J. and Sietchiping, R. (2001). Geoinformation for Sustainable Urbanization: Lessons learnt from UN-HABITAT experiences Geoinformation for Sustainable urbanization: Lessons learnt from UN-HABITAT experiences. , (254), pp.1-11.

Patel, D. (1988). Some Issues of Urbanisation and Development in Zimbabwe. pp.17-31.

Rema, E. (2012). Slum Upgrading: The Muungano Wa Wanavijiji ( MWW ) Vision Slum Upgrading: The Muungano Wa Wanavijiji ( MWW ) Vision.
Rosario Giusti de Pérez. Msc. Architecture, M.C.P.T.G.M. (Gerente G. (2009). Sustainable solutions for upgrading squatter developments.

Sadoun, B., Al-Bayari, O., Al-Azizi, J. and Al Rawashdeh, S. (2015). The BAU GIS system using open source mapwindow. , pp.1-12

Saleh, B. and Sadoun, B. (2006). Design and implementation of a GIS system for planning. , 6, pp.210-218.

Sliuzas, R. and Kuffer, M. (2004). A Participatory Approach to Monitoring Slum Conditions. , pp.19.

Šliužas, R.V. (2004). Managing Informal Settlements A Study Using GeoInformation in Dar es Salaam, Tanzania,

UN-Habitat, (2003). the Challenge of Slums,

UN-Habitat, (2014). Participatory Slum Upgrading Programme ( PSUP ). 